\title{
Editors Biography
}

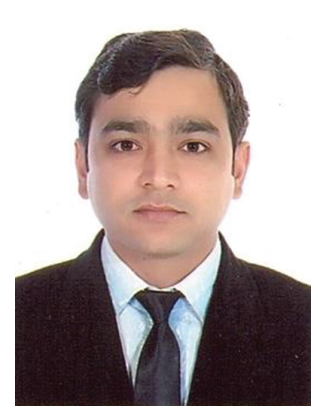

Dr. Amit Kumar is currently working as Assistant Professor at Department of Biotechnology, College of Natural and Computational Sciences, Debre Markos University (Ethiopia). He completed his Doctorate in Biotechnology from Indian Institute of Technology Roorkee (India). He is extensively involved in research on industrial enzymes, pulp \& paper biotechnology, biofuels production, and environmental biotechnology. He has published 30 research and review articles in various reputed international journals. He has also published two books entitled "Microbial Enzymes and Additives for the Food Industry" and "Nanobiotechnology for Green Environment". He has guided several graduate and post-graduate research projects.

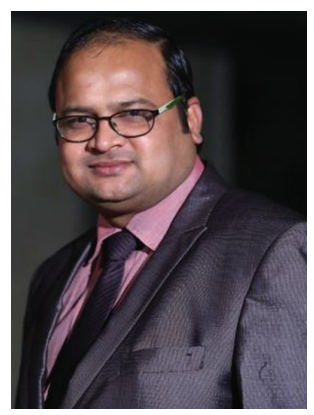

Dr. Puneet Pathak is currently working with Avantha Centre for Industrial Research \& Development (ACIRD), Patiala, Punjab (India) as Research Scientist in the Nanotechnology and Advanced Biomaterials Group since May 2012. He has completed his PhD (Industrial Microbiology) from Indian Institute of Technology Roorkee, Roorkee, Post-graduation (Microbiology) from Chaudhary Charan Singh University, Meerut and PG Diploma (Biotechnology) from UP Technical University, Lucknow. He has about 9 years research experience. His research interests are industrial enzymes, recycling (deinking), fermentation, biotechnological applications in pulp \& paper industry, nanocellulose, biorefinery, biofuels, valorization of lignocellulosic biomass and wastewater treatment. He has published 19 research papers in reputed peer reviewed international journals, 2 book chapters and attended 15 national and international conferences in India.

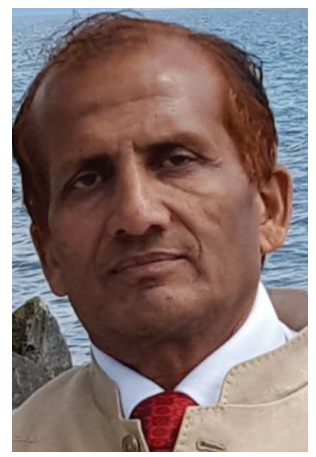

Dr. Dharm Dutt is a Professor at the Department of Paper Technology, Indian Institute of Technology Roorkee (India). He published about 180 research papers in national and international journals and supervised $19 \mathrm{PhD}$ thesis. He is honoured as a star performer seven times by the IIT Roorkee. He presented research papers in Rome (Italy), Katmandu (Nepal), Paris (France), Berlin (Germany), Jyvaskyla (Finland), Kyiv (Ukraine), London (UK), Indonesia, Milan (Italy), Stockholm (Sweden), Valencia (Spain) and Lausanne (Switzerland). He published two books namely 'Xylanases of Coprinellus disseminatus for Pulp and Paper Industry: Production, Characterization and Application in Biobleaching of Wheat Straw Pulp' and Cellulose Production and Biodeinking of Sorted Office Paper'. He has handled R\&D and consultancy projects of worth Rs. more than 3.5 crore. 
